\title{
Ethnic Differences in Satisfaction with Mental Health Services Among Psychiatry Patients
}

\author{
Suhaila Ghuloum ${ }^{1}$, Abdulbari Bener ${ }^{*}, 2,3$ and F. Tuna Burgut ${ }^{4}$ \\ ${ }^{1}$ Department of Psychiatry, Hamad Medical Corporation, Doha, Qatar \\ ${ }^{2}$ Department of Medical Statistics \& Epidemiology, Hamad General Hospital, Hamad Medical Corporation, Dept. of \\ Public Health, Weill Cornell Medical College, Doha, Qatar \\ ${ }^{3}$ Department of Evidence for Population Health Unit, School of Epidemiology and Health Sciences, The University of \\ Manchester, Manchester, UK \\ ${ }^{4}$ Department of Psychiatry, Weill Cornell Medical College, New York, NY 10021, USA
}

\begin{abstract}
Objective: The main aim of the study was to examine the impact of patients' ethnic diversity on the patient satisfaction level to psychiatry care and explores the satisfaction domains with mental health care.

Design: This is a prospective cross sectional study.

Setting: Psychiatry department of the Hamad Medical Corporation.

Subjects: The study sample was Qatari and other Arab nationals aged 18 to 65 years who visited the psychiatry department during the study period; April 2009 to August 2009. A total of 1300 adult patients were approached and 1054 (81.1\%) expressed their consent to participate in this study.

Method: A standard forward-backward procedure was applied to translate the English version of the PDRQ to Arabic. PDRQ was administered by pre-trained nurses among the psychiatry patients. The main outcome measures of the study were 13-item patient doctor relationship questionnaire (PDRQ) score and other 11 items assessing what patients need from psychiatrists. Also, Socio-demographic data of the patients was collected.

Results: Of the studied patients, there were 479 Qataris (45.4\%) and 575 other Arabs (54.6\%). There was a significant differences found between Qatari and Arab expatriate patients in marital status $(p=0.036)$, level of education $(p<0.001)$, occupation $(p<0.001)$, household income $(p<0.001)$, number of rooms in the house $(p<0.001)$ and people living in the house $(\mathrm{p}<0.001)$. Arab expatriate patients $(480 ; 55.9 \%)$ were more satisfied with psychiatry care than Qatari patients $(378 ; 44.1 \%)$ especially in the age group (18-34) years of both the ethnic groups $(164 ; 43.4 \%$ vs $214 ; 44.6 \%)$. Overall patient satisfaction level was significantly higher in literate Arab patients with secondary and university degree $(333 ; 69.3 \%)$, while it was lower in Qataris $(185 ; 49 \%)$. Satisfaction score was almost the same between Qatari and Arab expatriate patients with no significant difference. But satisfaction score was significantly higher in Spanish population in all domains of satisfaction compared to our study sample $(\mathrm{p}<0.0001)$.

Conclusions: The study findings revealed that there is no ethnic difference observed in the satisfaction score between Qatari and Arab expatriate patients in Qatar, but a significant difference was observed between Arab and Spanish psychiatry patients in all domains of satisfaction.
\end{abstract}

Keywords: Patient-doctor relationship, reliability and psychometric validation, mental illness, knowledge, Arab population.

\section{INTRODUCTION}

Patient satisfaction is a central indicator for health care quality. Patient satisfaction is regarded as an important outcome of care and it has been demonstrated to influence certain aspects of health related behavior [1]. It has been recognized that ethnicity of the patient independently influences physician behavior so that patients' evaluation of quality care can detect differences in physicians' practice

*Address correspondence to this author at the Department of Medical Statistics \& Epidemiology, Hamad Medical Corporation and Weill Cornell Medical College, P.O. Box 3050, Doha, Qatar;

Tel: +974- 439 3766; Fax: 974-439 3769;

E-mails: abener@hmc.org.qa, abb2007@qatar-med.cornell.edu style [2]. Patient satisfaction with health care is an important outcome since it can impact compliance with medical treatment, the clinician-patient relationship and use of health services. Earlier studies have shown that at least part of observed differences in satisfaction rates can be assigned to patient's demographic characteristics and among them, the diversity of their cultural backgrounds, and the expectations of the populations in different countries as important factors contributing to patient satisfaction [3,4]. Although physicians are increasingly in contact with patients from diverse social and cultural background, little is known of how patient diversity affects physicians' ability to identify patients' expectations. 
In the United States, numerous studies [5] have demonstrated racial inequalities in health care specifically minority populations have less access to care, use fewer health care resources and less satisfied with the care they receive than the majority white population. It was found that blacks were more satisfied with the care they received from black, as opposed to non-black physicians. Multinationalities and diverse cultural backgrounds are more or less normal features of modern societies all around the world [6].

The populations of Arabian Gulf countries include large proportions of Arab expatriate workers including Palestinian, Jordanians, Egyptians, Syrians, Lebanese, Sudanese etc. The life style of Arab expatriates is slightly different from nationals and it usually reflects more 'modernized' codes of conduct than those of the native population. At the same time, the majority of non-professional Arab expatriates are men who left their wives and children in their home countries. On the other hand, nationals have families of six to eight children, with more in polygamous marriages. These cultural backgrounds might influence patients' mental health care needs and expectation. Also, Bjorngaard et al. [7] reported that patients' satisfaction is highly dependent on socio-demographic characteristics and it is varied by populations.

Despite concern over their psychiatric treatment, little is known on ethnic differences on patient's satisfaction with psychiatric services and whether perceived ethnicity or discrepant understanding of illness experience is most relevant. In the last decade, there has been a growing interest in patient satisfaction as measures of outcome and quality of care in psychiatry [8]. But in the State of Qatar, no assessment of ethnic difference on patients' satisfaction with psychiatry care has been done. To the best of our knowledge, this is the first study in Qatar examining the ethnic diversity on the patient satisfaction towards mental health care needs.

\section{SUBJECTS AND METHODS}

This is a prospective cross sectional study based on the psychiatry hospital of the Hamad Medical Corporation among patients visiting the psychiatry hospital from April 2009 and July 2009. The study included Qatari and other Arab patients aged 18 to 65 years old who were attending the psychiatry hosptial during the study period. The psychiatry hospital is the main tertiary care center for mental illness in the State of Qatar. This hospital has a good referral system from the primary health care centers and the private sector clinics. This hospital succeeded in offering a multidisciplinary approach to mental health care.

The data was collected through a validated questionnaires self-administered with the help of pre-trained nurses. The questionnaire had three parts. The first part included the socio-demographic details of the patients, the second part is the English/Arabic version of the 13-item Patient Doctor Relationship Questionnaire PDRQ [9] and third part containing questions related to issues patients regularly have regarding their treatment plan [10]. The questionnaire was available in two main languages common among the visiting patients (English and Arabic). The original English version of the questionnaire was translated to Arabic by a professional translator and back translated to English to check for inconsistency. The questionnaire was designed to be self administered with assistance from pre-trained interviewers. Self administration of such instruments is necessary to avoid any bias in reporting due to hesitation. The interviewers were present to read out the question only incase the participants were illiterate or had difficulty reading. Patients were asked to answer the 13 questions by grading them from 1 to 5 ; with 1 for "not at all appropriate", 2 for "somewhat appropriate", 3 for "appropriate", 4 for "mostly appropriate" and 5 for "totally appropriate".

Qualified Nurses and Health Educators were instructed to structurally interview and assist the patients to complete the questionnaire. All patients who were willing to give consent and able to read Arabic text were approached since it was a self administered questionnaire. A total of 1300 eligible subjects were approached and 1054 patients participated in our study, thus giving a response rate of $81.1 \%$. Since the questionnaire assessed the patient satisfaction with psychiatrist, we interviewed only patients who had previous appointments with psychiatrists. Non-psychotic patients aged below 18 years of age, coming for the first time to psychiatry out-patient clinics for consultation and patients who refused to give consent were excluded from the study. The survey instrument was then tested on 100 patients who visited the outpatient clinics of the Psychiatry hospital which helped to decrease ambiguity in the questionnaire.

We have used the satisfaction scores mentioned in a similar study done with PDRQ questionnaire in Spain [10] for comparison purpose.

Student-t test was used to ascertain the significance of differences between mean values of two continuous variables of PDRQ items. Chi-square analysis was performed to test (two-tailed) were performed to test for differences in proportions of categorical variables between two or more groups. The level $\mathrm{p}<0.05$ was considered as the cut-off value for significance.

\section{RESULTS}

Table 1 shows the socio-demographic characteristics of the studied psychiatry patients according to nationality. Of the studied patients, 479 patients were Qataris (45.4\%) and 575 were other Arabs (54.6\%). Most of the Qatari $(200 ; 41.8 \%)$ and Arab expatriate patients $(257 ; 44.7 \%)$ were in the age group $(18-34)$ years. There were more male respondents in the Qatari group $(255 ; 53.2 \%)$ than in the other Arab group $(282 ; 49 \%)$. There was a significant association observed between Qatari and other Arab patients in terms of marital status $(\mathrm{p}=0.036)$, level of education $(\mathrm{p}<0.001)$, occupation $(\mathrm{p}<0.001)$, household income $(p<0.001)$, number of rooms in the house $(p<0.001)$ and people living in the house $(\mathrm{p}<0.001)$.

Table 2 examines the socio-demographic characteristics of the studied patients who were satisfied with psychiatry care according to nationality. Arab expatriate patients 
Table 1. Socio-Demographic Characteristics of the Studied Psychiatry Patients $(\mathrm{N}=1054)$

\begin{tabular}{|c|c|c|c|}
\hline Variables & $\begin{array}{l}\text { Qatari } \\
N=479\end{array}$ & $\begin{array}{c}\text { Other Arabs } \\
\mathrm{N}=575\end{array}$ & p-Value \\
\hline Age group & & & \multirow{6}{*}{0.557} \\
\hline$<35$ & $200(41.8)$ & $257(44.7)$ & \\
\hline $35-44$ & $125(26.1)$ & $153(26.6)$ & \\
\hline $45-54$ & $102(21.3)$ & $113(19.7)$ & \\
\hline $55-64$ & $22(4.6)$ & $29(5.0)$ & \\
\hline $65+$ & $30(6.3)$ & $23(4.0)$ & \\
\hline \multicolumn{3}{|l|}{ Gender } & \multirow{3}{*}{0.175} \\
\hline Males & $255(53.2)$ & $282(49)$ & \\
\hline Females & $224(46.8)$ & $293(51)$ & \\
\hline \multicolumn{3}{|l|}{ Marital Status } & \multirow{3}{*}{0.036} \\
\hline Single & $146(30.5)$ & $142(24.7)$ & \\
\hline Married & $333(69.5)$ & $433(75.3)$ & \\
\hline Have Children & $337(70.4)$ & $410(71.3)$ & 0.736 \\
\hline \multicolumn{3}{|l|}{ Education level } & \multirow{6}{*}{$<0.001$} \\
\hline Illiterate & $56(11.7)$ & $33(5.7)$ & \\
\hline Primary & $89(18.6)$ & $59(10.3)$ & \\
\hline Intermediate & $98(20.5)$ & $73(12.7)$ & \\
\hline Secondary & $171(35.7)$ & $212(36.9)$ & \\
\hline University & $65(13.6)$ & $198(34.4)$ & \\
\hline \multicolumn{3}{|l|}{ Occupation } & \multirow{7}{*}{$<0.001$} \\
\hline Student & $51(10.6)$ & $32(5.6)$ & \\
\hline Sedentary/Professional & $151(31.5)$ & $230(40)$ & \\
\hline Manual & $38(7.9)$ & $83(14.4)$ & \\
\hline Business & $30(6.3)$ & $14(2.4)$ & \\
\hline Army/Police & $33(6.9)$ & $13(2.3)$ & \\
\hline Housewife & $176(36.7)$ & $209(36.3)$ & \\
\hline \multicolumn{3}{|l|}{ Monthly household income } & \multirow{6}{*}{$<0.001$} \\
\hline$<5000$ & $66(13.8)$ & $167(29)$ & \\
\hline $5000-9999$ & $208(43.4)$ & $259(45)$ & \\
\hline $10,000-14,999$ & $102(21.3)$ & $92(16)$ & \\
\hline $15,000-19,999$ & $49(10.2)$ & $40(7)$ & \\
\hline$>20,000$ & $54(11.3)$ & $17(3)$ & \\
\hline Number of rooms in the house & $4.33 \pm 1.8$ & $2.87 \pm 1.3$ & $<0.001$ \\
\hline Number of people living in the house & $6.59 \pm 3$ & $5.15 \pm 2.3$ & $<0.001$ \\
\hline \multicolumn{3}{|l|}{ Place of living } & \\
\hline Urban & $374(78.1)$ & $448(77.9)$ & \multirow{2}{*}{0.948} \\
\hline Semi Urban & $105(21.9)$ & $127(22.1)$ & \\
\hline Do you have Internet at home & $296(61.8)$ & $366(63.7)$ & 0.535 \\
\hline Do you have TV at home? & $454(94.8)$ & $542(94.3)$ & 0.712 \\
\hline
\end{tabular}

Table 2. Socio-Demographic Characteristics of the Studied Psychiatry Patients who were Satisfied" with Psychiatry Care $(\mathrm{N}=\mathbf{8 5 8})$

\begin{tabular}{|c|c|c|c|}
\hline Variables & $\begin{array}{l}\text { Qatari } \\
\mathbf{N}=\mathbf{3 7 8}\end{array}$ & $\begin{array}{c}\text { Other Arabs } \\
\quad \mathbf{N}=\mathbf{4 8 0}\end{array}$ & p-Value \\
\hline \multicolumn{4}{|l|}{ Age group } \\
\hline$<35$ & $164(43.4)$ & $214(44.6)$ & \\
\hline $35-44$ & $99(26.2)$ & $122(25.4)$ & \\
\hline $45-54$ & $78(20.6)$ & $96(20.0)$ & 0.947 \\
\hline $55-64$ & $17(4.5)$ & $26(5.4)$ & \\
\hline $65+$ & $20(5.3)$ & $22(4.6)$ & \\
\hline \multicolumn{4}{|l|}{ Gender } \\
\hline Male & $221(58.5)$ & $255(53.1)$ & \multirow{2}{*}{0.135} \\
\hline Female & $157(41.5)$ & $225(46.9)$ & \\
\hline \multicolumn{4}{|l|}{ Marital Status } \\
\hline Single & $121(32.0)$ & $124(25.8)$ & \multirow{2}{*}{0.056} \\
\hline Married & $257(68.0)$ & $356(74.2)$ & \\
\hline Have Children & $258(68.3)$ & $337(70.2)$ & 0.588 \\
\hline \multicolumn{4}{|l|}{ Education level } \\
\hline Illiterate & $41(10.8)$ & $29(6.0)$ & \\
\hline Primary & $71(18.8)$ & $56(11.7)$ & \\
\hline Intermediate & $81(21.4)$ & $62(12.9)$ & $<0.001$ \\
\hline Secondary & $131(34.7)$ & $172(35.8)$ & \\
\hline University & $54(14.3)$ & $161(33.5)$ & \\
\hline \multicolumn{4}{|l|}{ Occupation } \\
\hline Not working & $96(25.4)$ & $126(26.3)$ & \\
\hline Sedentary/Professional & $131(34.7)$ & 190(39.6) & \\
\hline Manual & $34(9.0)$ & $73(15.2)$ & \\
\hline Business & $30(7.9)$ & $14(2.9)$ & $<0.001$ \\
\hline Army/Police & $25(6.6)$ & $12(2.5)$ & \\
\hline Housewife & $62(16.4)$ & $65(13.5)$ & \\
\hline \multicolumn{4}{|l|}{ Household income } \\
\hline$<5000$ & $48(12.7)$ & $134(27.9)$ & \\
\hline $5000-9999$ & 151(39.9) & $218(45.4)$ & \\
\hline $10,000-14,999$ & $86(22.8)$ & $78(16.3)$ & $<0.001$ \\
\hline $15,000-19,999$ & $43(11.4)$ & $35(7.3)$ & \\
\hline$>20,000$ & $50(13.2)$ & $15(3.1)$ & \\
\hline
\end{tabular}

$(480 ; 55.9 \%)$ were more satisfied with psychiatry care than Qatari patients $(378 ; 44.1 \%)$. The greatest level of satisfaction was observed in the age group of $(18-34)$ years of both Qatari and other Arab groups $(164 ; 43.4 \%$ vs $214 ; 44.6 \%)$, followed by $(35-44)$ years $(99 ; 26.2 \%$ vs $122 ; 25.4 \%$ ). Overall patient satisfaction level was significantly higher in literate Arab patients with secondary 
and university degree $(333 ; 69.3 \%)$, but it was lower in Qataris $(185 ; 49 \%)$. A significant difference was found in satisfaction level between Qatari and other Arab patients in their level of education $(p<0.001)$, occupation $(p<0.001)$ and monthly income $(\mathrm{P}<0.001)$.

Table 3 reveals the satisfaction score of the studied Qatari and other Arab patients with the psychiatry care. In general, the satisfaction level towards psychiatry care was good in both the ethnic groups (average score $\geq 3$ ), but no significant difference was observed between Qatari and Arab expatriate patients. The mean score was the same or very close for both the ethnic groups in all domains of satisfaction.

Table 3. Satisfaction Score of the Studied Patients with the Psychiatry Services* $(\mathrm{N}=1054)$

\begin{tabular}{|l|c|c|c|}
\hline \multicolumn{1}{|c|}{ Variables } & $\begin{array}{c}\text { Qatari } \\
\mathbf{N = 4 7 9}\end{array}$ & $\begin{array}{c}\text { Other Arabs } \\
\mathbf{N = 5 7 5}\end{array}$ & p-Value \\
\hline \hline My doctor understands me & $3.4 \pm 1.4$ & $3.6 \pm 1.3$ & 0.192 \\
\hline I trust my doctor & $3.4 \pm 1.0$ & $3.5 \pm 1.0$ & 0.057 \\
\hline My doctor is dedicated to help me & $3.9 \pm 1.0$ & $4.0 \pm 1.0$ & 0.113 \\
\hline I can talk to my doctor & $3.5 \pm 1.1$ & $3.5 \pm 1.1$ & 0.190 \\
\hline I feel content with my doctor's treatment & $3.2 \pm 1.0$ & $3.3 \pm 1.0$ & 0.161 \\
\hline My doctor helps me & $3.1 \pm 1.0$ & $3.2 \pm 1.1$ & 0.122 \\
\hline My doctor has enough time for me & $4.0 \pm 1.1$ & $4.0 \pm 1.1$ & 0.250 \\
\hline I benefit from the treatment of my doctor & $3.8 \pm 1.1$ & $3.8 \pm 1.1$ & 0.272 \\
\hline $\begin{array}{l}\text { My doctor and I agree on the nature of } \\
\text { my medical symptoms }\end{array}$ & $3.9 \pm 1.1$ & $3.9 \pm 1.1$ & 0.217 \\
\hline I find my doctor easily accessible & $3.8 \pm 1.1$ & $3.9 \pm 1.1$ & 0.148 \\
\hline $\begin{array}{l}\text { Thanks to my doctor, I feel better } \\
\text { (even if my doctor and I have no } \\
\text { further meeting) }\end{array}$ & $3.8 \pm 1.1$ & $3.8 \pm 1$ & 0.984 \\
\hline $\begin{array}{l}\text { Thanks to my doctor, I gained } \\
\text { new insight }\end{array}$ & $3.7 \pm 1.1$ & $3.8 \pm 1.1$ & 0.651 \\
\hline According to Spanish version of the PDRQ instrument. & $3.9 \pm 1.1$ & 0.021 \\
\hline
\end{tabular}

*According to Spanish version of the PDRQ instrument.

Table 4 compares the satisfaction score of psychiatry patients in Arab population in Qatar and Spain. Satisfaction score was significantly higher in Spanish population than in the study sample in all the areas except in agreeing the nature of medical symptoms between psychiatrist and patients. The mean score of the Spanish psychiatry patients was above the score 4 "mostly appropriate", while it was above 3 "appropriate" in the study sample. The psychiatry patients in Spain were most satisfied with trusting the psychiatrist $(4.48 \pm 0.80)$, dedication of psychiatrist $(4.35 \pm 0.85)$ and helping mentality of psychiatrist $(4.38 \pm 0.82)$, while the most satisfied areas of the Arab expatriate patients were dedication (3.95 \pm 1.02$)$ and availability of Psychiatrists

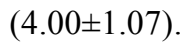

Table 4. Comparison Betwceen Qatar and Spain in Satisfaction Score of the Studied Patients with the Psychiatry Services* $(\mathrm{N}=1054)$

\begin{tabular}{|c|c|c|c|}
\hline \multirow{2}{*}{ Variables } & Qatar & Spain $^{*} 10^{*}$ & \multirow{2}{*}{ P-Value } \\
\hline & $\operatorname{Mean} \pm$ SD & $\operatorname{Mean} \pm$ SD & \\
\hline My doctor understands me & $3.50 \pm 1.32$ & $4.31 \pm 0.92$ & $<0.0001$ \\
\hline I trust my doctor & $3.49 \pm 0.98$ & $4.48 \pm 0.80$ & $<0.0001$ \\
\hline My doctor is dedicated to help me & $3.95 \pm 1.02$ & $4.35 \pm 0.85$ & $<0.0001$ \\
\hline I can talk to my doctor & $3.50 \pm 1.10$ & $4.27 \pm 0.87$ & $<0.0001$ \\
\hline $\begin{array}{l}\text { I feel content with my doctor's } \\
\text { treatment }\end{array}$ & $3.30 \pm 1.03$ & $4.34 \pm 0.87$ & $<0.0001$ \\
\hline My doctor helps me & $3.15 \pm 1.06$ & $4.38 \pm 0.82$ & $<0.0001$ \\
\hline My doctor has enough time for me & $4.00 \pm 1.07$ & $4.23 \pm 1.01$ & 0.0063 \\
\hline $\begin{array}{l}\text { I benefit from the treatment of my } \\
\text { doctor }\end{array}$ & $3.80 \pm 1.09$ & $4.29 \pm 0.88$ & $<0.0001$ \\
\hline $\begin{array}{l}\text { My doctor and I agree on the nature } \\
\text { of my medical symptoms }\end{array}$ & $3.91 \pm 1.13$ & $4.30 \pm 0.96$ & $<0.2029$ \\
\hline I find my doctor easily accessible & $3.81 \pm 1.10$ & $4.21 \pm 1.00$ & $<0.0001$ \\
\hline Thanks to my doctor, I feel better & $3.81 \pm 1.05$ & $4.32 \pm 0.86$ & $<0.0001$ \\
\hline $\begin{array}{l}\text { Thanks to my doctor, I gained new } \\
\text { insight }\end{array}$ & $3.74 \pm 1.07$ & $3.34 \pm 0.89$ & $<0.0001$ \\
\hline $\begin{array}{l}\text { I can handle my medical symptoms } \\
\text { now (even if my doctor and I have } \\
\text { no further meeting) }\end{array}$ & $3.78 \pm 1.16$ & $3.99 \pm 1.07$ & $<0.0137$ \\
\hline
\end{tabular}

\section{DISCUSSION}

Ethnic differences in rates of mental illness, and access to and experience of mental health services, have been a long standing debate and concern. The effective provider-patient communication is directly linked to improved patient satisfaction, adherence, and subsequently, health outcomes. Thus, when socio-cultural differences between patient and provider are not understood, explored or communicated during the clinical encounter, patient dissatisfaction, nonadherence and poorer health outcomes may result. However, the present study shed some light on the ethnic differences on patients' satisfaction to psychiatry care. The study examined the patients' satisfaction rate of natives and nonnative group, Arab expatriates, residing in the State of Qatar. Our study produces some interesting results that ethnic groups did not differ significantly in patient satisfaction score because of the same culture and homogeneous characteristics of the ethnic groups.

The satisfaction score of the Qatari and other Arab psychiatry patients rated above 3 which is "appropriate" for the 13 different satisfaction areas. This shows that overall, both the ethnic groups were satisfied with the services provided by the psychiatrists. There was no significant difference observed between Qatari and other Arab 
psychiatry patients in their satisfaction score. The mean score was almost same in all satisfaction areas. In some fields, there are small differences showing lower satisfaction in Qatari patients compared to other Arabs like understanding, dedication and accessibility of psychiatrists and self content with the treatment. The possible explanation for this dissatisfaction is that the nationals always prefer going abroad for treatment and they might prefer consultants from western countries. Moreover, in the State of Qatar, health services are free for nationals. These slight differences show the necessity that psychiatrists should be more attentive to Qatari patients showing empathy and understanding to the patients' problems and expectations. Another explanation for such tiny differences could be the higher volume of non-native patients in the survey.

At the same time, when it is compared with the Spanish patients, patients' ratings of satisfaction with mental health services is significantly lower for Qatari and Arab expatriate patients. This result supports the other studies $[11,12]$ on the impact of patients' ethnic diversity on the patient satisfaction rates. A study done by Cox [11] indicated that although there were no African American-White differences in satisfaction with psychiatry hospital services, African American were less satisfied with the services. Bhugra et al. reported that Black mental health patients tended to be more dissatisfied with GP services than white patients [12]. Parkman et al. [13] mentioned in his study that patients' ratings of satisfaction with mental health services are significantly worse for UK born Black Caribbean than other psychiatry patients in South London. On the contrary, few studies have found small or no ethnic differences in satisfaction with mental health care $[14,15]$. These study findings show that quality of care as assessed by the patients in terms of overall patient satisfaction does differ significantly regarding their ethnic backgrounds. The ethnic differences in patients' satisfaction might be for the reason that patients from racial and ethnic minority groups use fewer health care services and are less satisfied with their care than patients from the majority population as reported by Saha et al. [16]. These disparities may be attributable in part to racial or cultural difference between patients and their physicians.

We found few associations between satisfaction and socio-demographic factors. The greatest level of satisfaction was observed in the age group of $18-34$ years of both the ethnic groups $(164 ; 43.4 \%$ vs $214 ; 44.6 \%)$. Also, the satisfaction level was significantly higher in educated Qatari $(185 ; 49 \%)$ and Arab expatriate $(333 ; 69.3 \%)$ patients because education is likely a proxy for knowledge, greater attentiveness to mental health information and awareness of the availability and acceptability of seeking help for mental health problems. The respondents who were working in sedentary and professionals job were more satisfied with psychiatry care compared to other groups; Qataris $(131 ; 34.7 \%)$ and other Arabs (190;39.6\%). Thus, the differences observed between these two ethnic groups were largely due to different relationship among demographics to mental health service use. El Islam [17] reported that like conservative patients in other societies, traditional Arab patients have been culturally conditioned to reveal little or no depth of emotions to strangers including mental health professionals that could lead to dissatisfaction. The findings showed that in Qatar, age differences in patient satisfaction to mental health needs deserve attention. The oldest group among Qataris and Arab expatriates were not satisfied with mental health services.

It is noteworthy that there is no ethnic difference found between Qatari and Arab expatriates. But, due to the nature of the study, there might be ethnic differences between Arab population and other expatriates residing in Qatar. Differences in satisfaction to services may be a result of cultural preferences, language limitations, institutional exclusions or financial barriers. The cross cultural psychiatry movement has developed alongside a growing awareness that ethnicity; cultural background and race are critical factors in determining the way in which mental illness is assessed and managed.

The study has few limitations that must be noted. The two ethnic groups involved in this study are Qataris and other Arabs. Qataris are nationals and they are of homogenous type, but all other Arabs were lumped together in a single category. Hence, they are heterogeneous and they represent a slight difference in their culture and practice. Also, there might be communication gap between patients and non-Arab Psychiatrists. Secondly, the sample size approached might not be representative at the time of data collection. Another potential limitation is that the interview time taken for patients might vary from one patient to another which will affect their responses to questions. However, our study represents an initial effort to examine the patient satisfaction with mental health services.

\section{CONCLUSIONS}

The study findings revealed that there is no ethnic difference observed in the satisfaction score between Qatari and Arab expatriate patients in Qatar, but a significant difference was observed between Arab and Spanish psychiatry patients in all the domains of satisfaction. Overall, both the ethnic groups, Qatari and other Arab patients were satisfied with psychiatric care especially in the availability and the dedication of psychiatrists. The overall satisfaction was little lower in native group compared to non-natives. Ethnic groups differed significantly in their sociodemographic factors like education, occupation and monthly household income.

\section{ACKNOWLEDGEMENTS}

This study was generously supported and funded by the Qatar National Research Fund- QNRF NPRP 30-6-7-38. The authors would like to thank the Hamad Medical Corporation for their support and ethical approval.

\section{REFERENCES}

[1] Donabedian A. The Lichfield Lecture. Quality assurance in health care: consumers' role. Qual Health Care 1992; 1: 247-51.

[2] Gross DA, Zyzanski SJ, Borawski EA, Cebul RD, Stange KC. Patient satisfaction with time spent with their Physician. J Fam Pract 1998; 47: 133-7.

[3] Calnan M, Katsoyiannopulos V, Ovcharow VK, Prokhorskas R, Ramic H, Williams S. Major detriments of consumer satisfaction 
with primary care in different health systems. Fam Pract 1994; 11: 468-78.

[4] Greenwood N, Key A, Burns T, Bristow M, Sedgwick P. Satisfaction with in-patient psychiatric services. Relationship to patient and treatment factors. Br J Psychiatry 1999; 174: 159-63.

[5] Lillie-Blanton M, Alfaro-Correa A. In the Nation's interest: equity in Access to health care. Washington, DC: Joint Center for Political and Economic Studies 1995.

[6] Rothschild SK. Cross-cultural issues in primary care medicine. Dis Mon 1998; 44: 293-319.

[7] Bjorngaard JH, Ruud T, Garratt A, Hatling T. Patients' experiences and clinicians' ratings of the quality of outpatient teams in psychiatric care units in Norway. Psychiatr Serv 2007; 58(8): 11027.

[8] Noble LM, Douglas BC, Newman SP. What do patients want and do we want to know? A review of patient's requests of psychiatric services. Acta Psychiatr Scand 1999; 100(5): 321-7.

[9] Van der Feliz-Cornelis CM, Van Oppen P, Van Marwijk HWJ, De Beurs E, Van Dyck R. A patient-doctor relationship questionnaire (PDRQ-9) in primary care: development and psychometric evaluation. Gen Hosp Psychiatry 2004; 26: 115-20.

[10] Mingote AJC, Moreno JB, Rodriguez CR, Galvex HM, Ruiz LP. Psychometric validation of the Spanish version of the Patient-
Doctor relationship Questionnaire (PDRQ). Actas Esp Psiquiatr 2009; 37(2): 94-100.

[11] Cox C. Outcomes of hospitalization: factors influencing the discharges of African American and White dementia patients. Soc Work Health Care 1996; 23: 23-38.

[12] Bhugra D, Harding C, Lippett R. Pathways into care and satisfaction with primary care for Black patients in South London. J Ment Health 2004; 13: 171-83.

[13] Parkman S, Davies S, Leese M, Phelan M, Thornicroft G. Ethnic differences in Satisfaction with mental health services among representative people with psychoses in South London: PRISM Study 4. Br J Psychiatry 1998; 171: 582.

[14] Commander MJ, Cochrane R, Sashidharan SP, Akilu F, Wildsmith E. Mental health care for Asian. Black and white patients with nonaffective psychoses: Pathways to the psychiatric hospital, in-patient after care. Soc Psychiatry Psychiatr Epidemiol 1999; 34: 484-91.

[15] Callan A, Littlewood R. Patient satisfaction: ethnic origin or explanatory model? Int J Soc Psychiatry 1998; 44: 1-11.

[16] Saha S, Komaromy M, Koepsell TD, Bindman AB. Patientphysician racial concordance and the perceived quality and use of health care. Arch Intern Med 1999; 159: 997-1004.

[17] El-Islam MF. The woman with one foot in the past. In: Tseng WS, Streltzer J, Eds. Culture and psychotherapy. Washington, DC: American Psychiatric Press 2001; pp. 27-41.

(C) Ghuloum et al.; Licensee Bentham Open.

This is an open access article licensed under the terms of the Creative Commons Attribution Non-Commercial License (http://creativecommons.org/licenses/by-nc/ 3.0/) which permits unrestricted, non-commercial use, distribution and reproduction in any medium, provided the work is properly cited. 